\title{
Reformer and Membrane Modules (RMM) for Methane Conversion Powered by a Nuclear Reactor
}

\author{
M. De Falco' ${ }^{1}$ A. Salladini2, E. Palo ${ }^{3}$ and G. Iaquaniello ${ }^{3}$ \\ ${ }^{1}$ Faculty of Engineering, University Campus Bio-Medico of Rome, \\ 2Processi Innovativi, L'Aquila, \\ ${ }^{3}$ Tecnimont KT S.p.A., Rome, \\ Italy
}

\section{Introduction}

In the last few years, significant developments in membrane science and the vision of process intensification by multifunctional reactors have stimulated the academic and industrial research focused on membrane reactor application to chemical processes (Mendes et al., 2010, Dittmeyer et al., 2001, Basile et al., 2005a, De Falco et al., 2007). From these works, the increase of the reactants conversion above the equilibrium values appears to be possible when a reaction products at least is removed through the membrane. As stated in the following, the integration of selective membrane in a chemical process can be twofold:

- $\quad$ directly inside the reaction environment (Integrated Membrane Reactor - IMR);

- $\quad$ after the reaction step (Reaction and Membrane Module - RMM).

In this chapter a methane steam reforming (MSR) RMM pre-industrial plant, designed and tested to investigate at an industrial scale level the plant performance, is presented.

A major benefit of the proposed RMM configuration is the shift of steam reforming reactions chemical equilibrium by removing the hydrogen produced at high temperature, thanks to the integration of highly selective Pd-based membranes and enhancing the final product yield. By this way, the process can operate at a temperature as low as $600-650^{\circ} \mathrm{C}$ in comparison to $850-880^{\circ} \mathrm{C}$ needed in conventional plants, and enable the use of low temperature heat source as helium heated in a nuclear reactor.

This chapter reports, firstly, membrane reactor concept, selective membrane typologies and integration strategies; then it discusses the experimental data gathered over 1000 hours of testing on an industrial pilot unit in terms of feed conversion at different operating parameters and elaborates such data in order to optimize the overall architecture, defining the maximum achievable feed conversion under different scenario of heat integration. Finally, a membrane reactor perspectives analysis, mainly focused on integration with nuclear reactors for steam reforming reactor heat duty supplying, is reported in order to understand which technical and economical targets have to be reached in the next future for a commercial diffusion.

The plant discussed in this chapter, placed in Chieti Scalo (Italy), is characterized by a $\mathrm{H}_{2}$ design capacity of $20 \mathrm{Nm}^{3} / \mathrm{h}$ and it operates with three $\mathrm{Pd}$ and $\mathrm{Pd} / \mathrm{Ag}$ based membranes for 
hydrogen separation. It was developed in the framework of the Italian FISR Project "Pure hydrogen from natural gas reforming up to total conversion obtained by integrating chemical reaction and membrane separation", which grouped Italian universities, and the engineering society Tecnimont KT (TKT), cooperating in the development of each critical point of this innovative technology, such as membrane manufacture and assembling and catalyst optimization, resulting in the plant design and operation finally carried out by TKT. This installation, the first of this type and size, makes it possible to completely understand the potential of selective membrane application in industrial high-temperature chemical processes.

\section{Membrane reactor concept and benefits}

A membrane reactor (MR) is a system coupling reaction and separation of one or more products, with the separation operation performed by a selective membrane. Although not yet very used at industrial scale, MRs are attracting the attention of scientists and engineers in the last two decades and many interesting papers have appeared in the literature on their performance and possible applications in many fields of chemical and biochemical industries. An excellent review about these topics has appeared in 2002 by Sanchez Marcano \& Tsotsis (Sanchez Marcano \& Tsotsis, 2002). Moreover, the Italian company Tecnimont-KT has developed and fabricated a membrane reactor methane steam reforming pre-industrial prototype with a pure hydrogen production capacity of $20 \mathrm{Nm}^{3} / \mathrm{h}$ (De Falco et al., 2011a) and described in paragraph 3.

MR concept is based on the removal of a reaction product in order to avoid the reaction equilibrium conditions to be achieved and promoting reaction kinetics.

Most of industrial chemical reactions are reversible reactions, thermodynamically limited since equilibrium conditions cannot be overcome in the reacting mixture. From a thermodynamic point of view, equilibrium is represented by a constraint, i.e. equilibrium constant, on mole concentrations, temperature and pressure, derived from the second principle of thermodynamics. When equilibrium conditions are achieved, no net change in state variables is observed.

From a kinetics point of view it means that at equilibrium the reaction rate of the direct reaction is equal to the reaction rate of the inverse reaction. Taking as reference an elementary reversible reaction:

$$
\mathrm{A} \leftrightarrow \mathrm{B}
$$

the kinetics scheme is characterized by a direct reaction rate $(A \rightarrow B)$ and an inverse reaction rate $(\mathrm{B} \rightarrow \mathrm{A})$. Initially, if only component $\mathrm{A}$ is fed to the reactor, the direct reaction is promoted. Then, as the concentration of component B increases, the inverse reaction is supported as far as the direct reaction and inverse reaction rates assumes a similar value (equilibrium conditions) and reaction stops.

Integrating a selective membrane into the reaction environment allows to remove the reaction product (B), avoiding the increase of inverse reaction and promoting the direct reaction kinetics. By this way, two main benefits are reached:

- removing one or more reaction products as they are generated allows to obtain conversions higher than equilibrium values;

- if the membrane is very selective with regard to a specific product, it is possible to support reaction and product separation in one single compact device, obtaining a very pure compound. 
In this paragraph, the two main MR configurations are described and compared; then properties of selective membranes, suitable to be integrated in industrial chemical processes, are reported.

\subsection{MR configurations}

A selective membrane can be integrated in a chemical process by two different configurations:

- when the selective membrane is integrated directly in the reaction environment and the reaction product is removed as it is produced, the system is called Integrated Membrane Reactor (IMR);

- if the selective membrane is placed outside the reactor, in a proper unit located downstream, the system is called Staged Membrane Reactor (SMR) or Reactor and Membrane Module (RMM).

\subsubsection{Integrated membrane reactor}

An Integrated Membrane Reactor (IMR) is a compact device in which a selective membrane is directly assembled inside the reaction environment. The simplest configuration is composed by two concentric tubes, where catalyst pellets are packed in annular zone (Fig. 1) or in the inner tube (Fig.2), which is the membrane itself. Therefore, the reactor is composed by two zones:

- the reaction zone, where the catalyst is packed;

- the permeation zone, where the product permeated through the selective membrane is collected and carried out by a sweeping gas fed co-currently or counter-currently.

The membrane integration can be made also assembling many smaller tubes, so thus increasing the specific membrane surface on reactor volume and consequently the global permeated hydrogen flow.

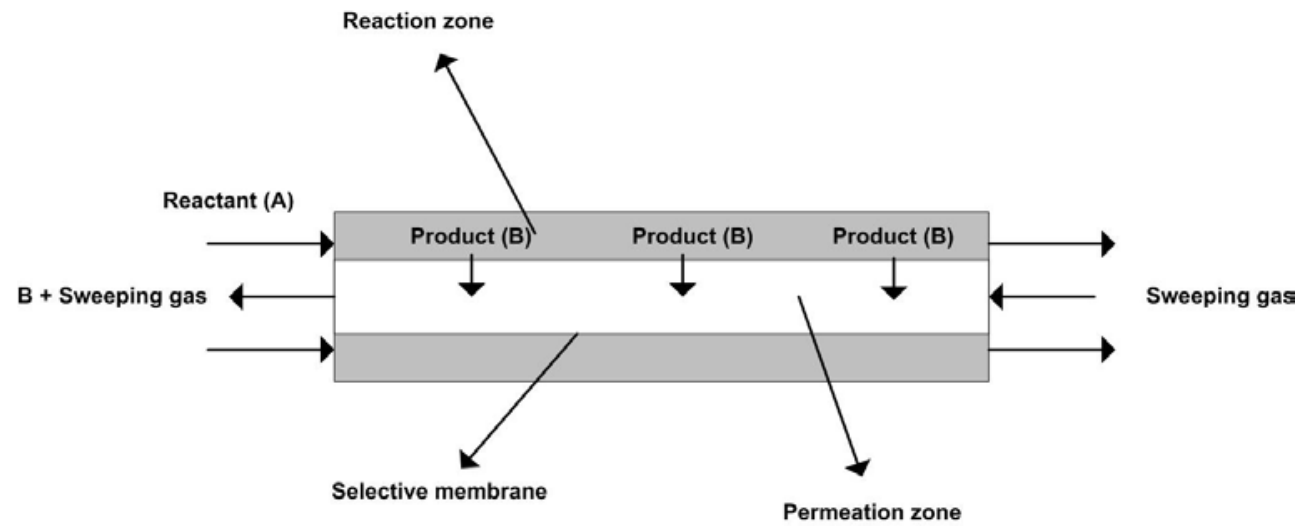

Fig. 1. IMR with catalyst packed in the annular zone.

\subsubsection{Reactor and membrane module}

The RMM configuration is composed by steps of reaction followed by steps of products separation through selective membranes. Fig. 3 shows a two reaction-separation modules 
process layout: taking as reference the reaction (1), the reactant $A$ is fed to the first reaction step where it is partially converted in the product $B$; then, the mixture $A+B$ is sent to the separation module where component $B$ is partially separated and recovered. The A-rich mixture is then fed to the second reaction step where the direct reaction is further promoted and the B produced is separated again in the second membrane module.

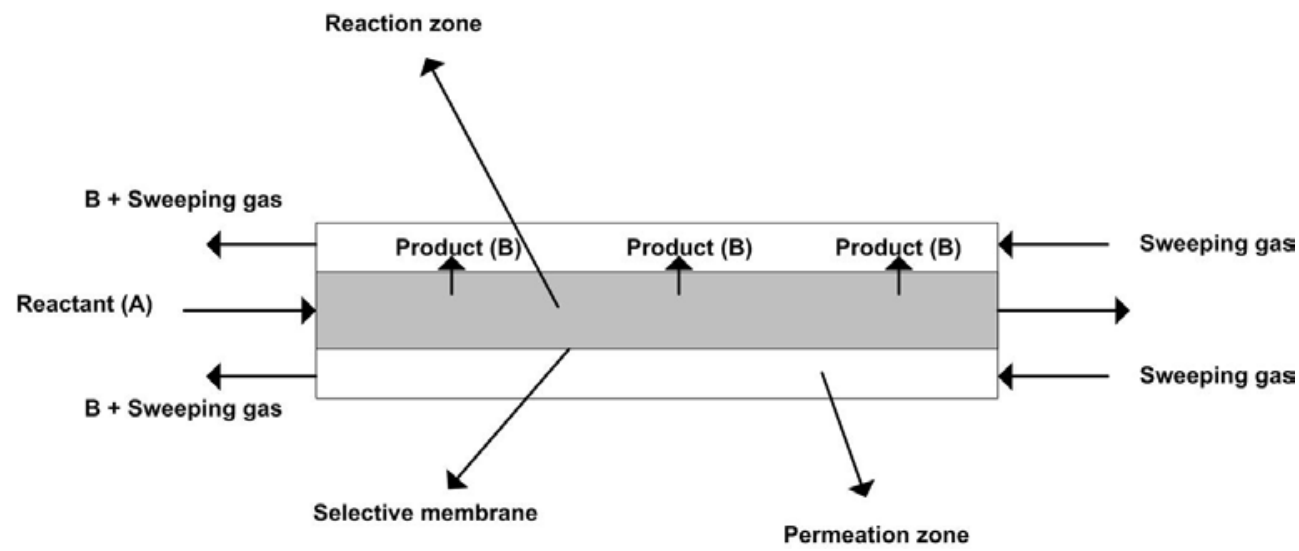

Fig. 2. IMR with catalyst packed in the inner tube.

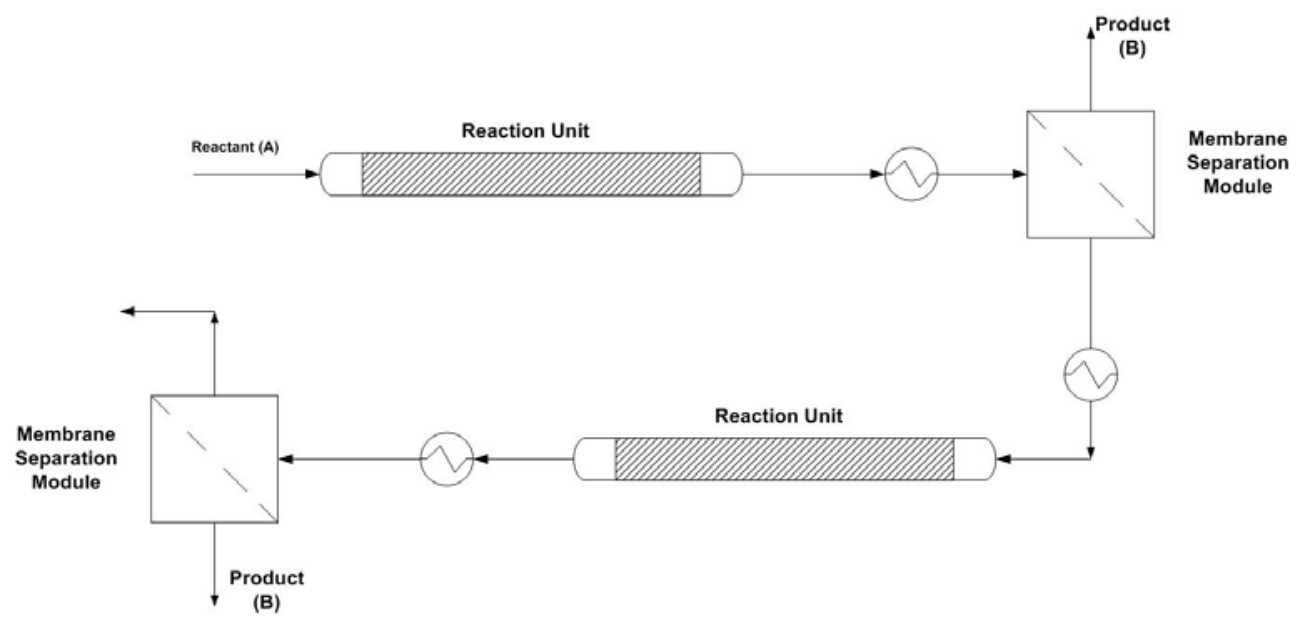

Fig. 3 RMM configuration.

\subsubsection{MR configurations comparison}

Both MR configurations assure crucial benefits in respect to the traditional technology. In order to compare the traditional technology and the membrane based one, we take as an example the methane steam reforming, which is the most applied process for industrial production of hydrogen. The conventional steam methane reforming system is composed of 
a steam reformer, a shift converter and a hydrogen purifier based on the pressure swing adsorption (PSA).

The reactions that occur during this process are the following (2-4):

$$
\begin{array}{lll}
\mathrm{CH}_{4}+\mathrm{H}_{2} \mathrm{O}=\mathrm{CO}+3 \mathrm{H}_{2} & \text { Methane steam reforming } & \Delta \mathrm{H}^{0}{ }_{298 \mathrm{~K}}=+206 \mathrm{~kJ} / \mathrm{mol} \\
\mathrm{CO}+\mathrm{H}_{2} \mathrm{O}=\mathrm{CO}_{2}+\mathrm{H}_{2} & \text { Water gas shift } & \Delta \mathrm{H}^{0}{ }_{298 \mathrm{~K}}=-41 \mathrm{~kJ} / \mathrm{mol} \\
\mathrm{CH}_{4}+2 \mathrm{H}_{2} \mathrm{O}=\mathrm{CO}_{2}+4 \mathrm{H}_{2} & \text { Overall reaction } & \Delta \mathrm{H}^{0_{298 K}}=+165 \mathrm{~kJ} / \mathrm{mol}
\end{array}
$$

Steam reforming process is highly endothermic and equilibrium limited. To sustain global endothermic reaction and achieve high feed conversion, it is necessary to burn a part of methane feedstock in furnaces and operate at high temperature $\left(800-850^{\circ} \mathrm{C}\right)$. This implies a reduced process global efficiency, increased greenhouse gas (GHG) emissions and a stronger dependence of hydrogen cost on the natural gas cost. Thus, on these bases the integration of a hydrogen selective membrane would allow:

- a strong reduction of the reaction temperature to about $450-650^{\circ} \mathrm{C}$, since a high temperature is not required to reach natural gas conversion to hydrogen $>90 \%$. The lower operating temperature leads to: a higher efficiency of the heat transfer from the external source to the reactor; a lower exergy of the heating fluid in comparison with the high temperature combustion gas used in the furnace, which means a lower heating cost; the possibility to use different heating fluids, depending on their availability; the possibility to fabricate tubular reactor by cheaper alloy steels.

- Process efficiency increase. The global process efficiency increases from the $65-80 \%$ of the traditional technology up to $85 \%$ and more for all the plant sizes.

- Combustion fuel saving. Reduction of reaction temperature leads to the reduction of process heat duty. The heat flux from the external source to the catalytic bed should be $30-40 \mathrm{~kW} / \mathrm{m}^{2}$ instead of $80 \mathrm{~kW} / \mathrm{m}^{2}$ about of the traditional process (Dybkjaer, 1995).

To make a comparison between IMR and RMM configurations (De Falco et al., 2011b), it is a worth assessment that:

- $\quad$ at the same operating conditions, IMR leads to better performance, since an integrated membrane reactor is equivalent to an infinite series of reactor + separator modules.

- On the other hand, in the RMM configuration, reaction and separation operating conditions can be optimized separately. In some cases it could be a crucial benefit. For example, in a methane reforming process, dense supported membranes (as Pd-based membranes on ceramics or Porous Stainless Steel) are assembled to selectively remove the hydrogen produced by the reactions. These membranes have to respect a stringent temperature threshold $\left(\mathrm{T}<500^{\circ} \mathrm{C}\right)$ in order to guarantee a proper selective layer support adherence. But a too low temperature limits the endothermic reaction thermodynamic conversion and the reaction rates. If an IMR is applied, a compromise solution has to be found, while in a RMM process the operating conditions of reaction and separation units can be imposed separately.

At the actual selective membrane state-of-the-art, RMM seems to be the leading architecture for membrane safety, for the multi-optimization potentiality and for its maintenance easiness. Surely, a future improvement of membrane performance, mainly for operating stability, would promote the applications of IMRs. 


\subsection{Selective membranes properties}

Figure 4 shows a general classification of membranes, based on their nature, separation regime and geometry.

The classification based on the membrane nature distinguishes them into biological and synthetic ones, differing completely for functionality and structure.

Biological membranes are easy to be fabricated but they present many drawbacks such as limited operating temperature (below $100{ }^{\circ} \mathrm{C}$ ) and $\mathrm{pH}$ range, problems related to the cleanup and susceptibility to microbial attack due to their natural origin (Xia et al., 2003).

Synthetic membranes can be subdivided into organic (polymeric) and inorganic (ceramic, metallic). Polymeric membranes operate between $100-300{ }^{\circ} \mathrm{C}$, inorganic membranes above $200{ }^{\circ} \mathrm{C}$. Surely, for industrial chemical process, the inorganic membranes are the most interesting.

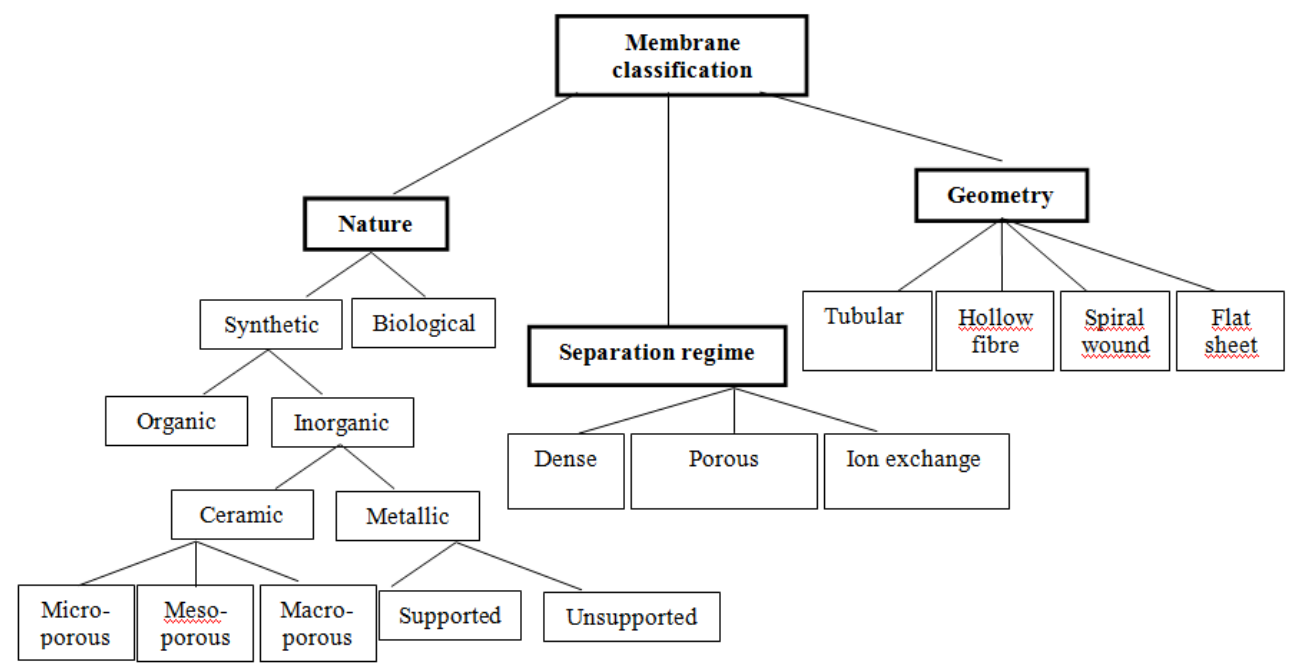

Fig. 4. Scheme of a general classification of the membranes (De Falco, 2011b).

Concerning with separation mechanism, there are three mechanisms depending on specific properties of the components (Mulder, 1996):

- separation based on molecules/membrane surface interactions (e.g. multi-layer diffusion) and/or difference between the average pore diameter and the average free path of fluid molecules (e.g. Knudsen mechanism);

- separation based on the difference of diffusivity and solubility of substances in the membrane: solution/diffusion mechanism;

- $\quad$ separation due to the difference in charge of the species to be separated: electrochemical effect.

In the following paragraphs, a pre-industrial application of selective membrane is described: the membrane applied is a Pd-alloy based supported membrane (dense inorganic membrane) for the separation of the hydrogen produced in a methane steam reformer. The Pd-based membranes are characterized by much high hydrogen selectivity and follow a solution/diffusion mechanism, composed by the following steps (Fig. 5): 
- dissociation of molecular hydrogen at the gas/metal interface;

- $\quad$ adsorption of the atomic hydrogen on membrane surface;

- dissolution of atomic hydrogen into the palladium matrix;

- diffusion of atomic hydrogen through the membrane;

- re-combination of atomic hydrogen to form hydrogen molecules at the gas/metal interface;

- desorption of hydrogen molecules.

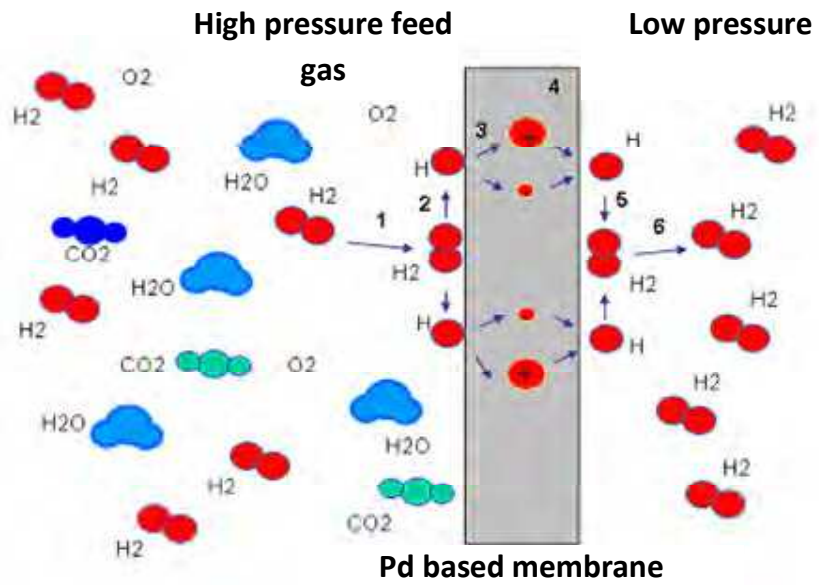

Fig. 5. Mechanism of permeation of hydrogen through metal membranes: 1) dissociation, 2) adsorption, 3) ionization, 4) diffusion, 5) recombination, 6) desorption (De Falco, 2011b).

When the pressure is relatively low, the diffusion is assumed to be the rate-limiting step and the permeation flux is described by Sieverts-Fick's law (5):

$$
\mathrm{J}_{\mathrm{H}_{2}, \text { Sieverts-Fick }}=\mathrm{Pe}_{\mathrm{H}_{2}} / \delta \cdot\left(\mathrm{p}_{\mathrm{H}_{2} \text {,ret }}^{0.5}-\mathrm{p}_{\mathrm{H}_{2} \text {,perm }}^{0.5}\right)
$$

where $\delta$ is the membrane thickness, $\mathrm{p}_{\mathrm{H}_{2} \text {,ret }}$ and $\mathrm{p}_{\mathrm{H}_{2} \text {,perm }}$ are the hydrogen partial pressure in the retentate and permeate respectively, $\mathrm{Pe}_{\mathrm{H} 2}$ is the membrane permeability calculated by Arrhenius law thus defined (6):

$$
\mathrm{Pe}_{\mathrm{H}_{2}}=\mathrm{Pe}_{\mathrm{H}_{2}}^{0} \exp \left(-\mathrm{E}_{\mathrm{a}} / \mathrm{RT}\right)
$$

where $\mathrm{Pe}^{0}$ is the pre-exponential factor, $\mathrm{E}_{\mathrm{a}}$ the apparent activation energy, $\mathrm{R}$ the universal gas constant and $\mathrm{T}$ the absolute temperature.

Although a strong effort has been devoted to Pd-based membrane development by research and industrial institutions during these years, these membranes have not yet reached a commercial stage due to some technical issues as long term permeance and selectivity stability, but also to the cost related to their manufacture. In the following paragraphs, the pre-industrial plant fabricated by Tecnimont-KT in Italy is described and experimental tests results are reported. Then, the concept of coupling membrane reactors to nuclear reactors is analyzed from a technical and an economic point of view. 


\section{Reformer and membrane modules (RMM) plant}

\subsection{Plant description}

As reported above, a pre-industrial natural gas steam reforming RMM plant has been developed by Tecnimont-KT in Chieti Scalo. The plant process scheme is reported in Figure 6a together with a bird-eye view (Figure $6 \mathrm{~b}$ ) of the constructed industrial test plant which covers an area of $1000 \mathrm{~m}^{2}$.
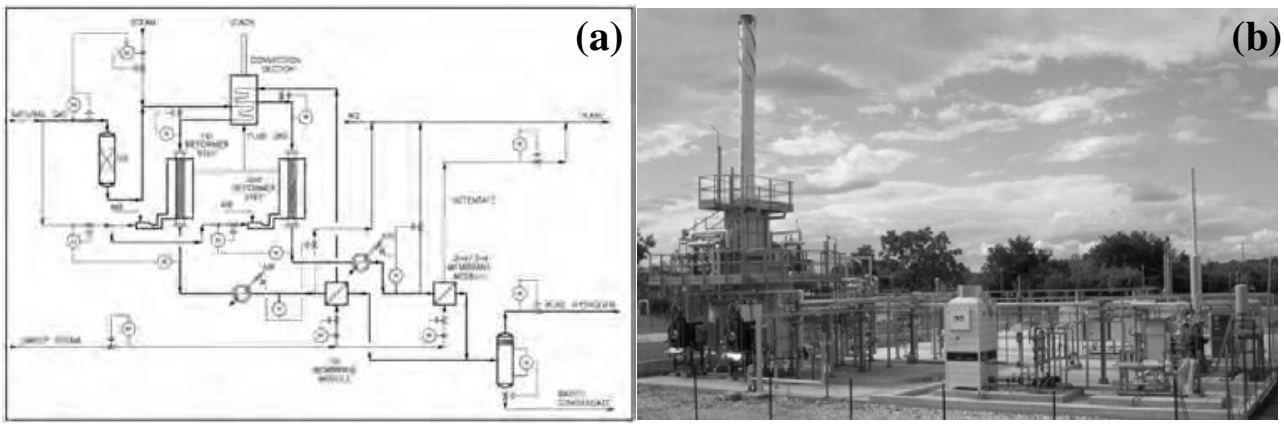

Fig. 6. Process scheme (a) and bird-eye view (b) of the industrial test plant

The plant is composed by two-step reformers and two membrane modules working respectively in the temperature range $550-650^{\circ} \mathrm{C}$ and $400-450^{\circ} \mathrm{C}$.

Natural gas is supplied from battery limits or from cylinders at 20 barg. A portion of natural gas is fed through a flow controller to the desulphurisation reactor (DS) for sulphur compounds removal to content lower than $0.1 \mathrm{ppm}$. The residual is used as fuel gas, reduced at 0.3 barg. The desulphurised feed is mixed with steam, produced separately by a real hot oil boiler, preheated in the convection section and fed to the first reforming stage. More specifically, each reformer module is composed by two main sections: (i) a radiant tube, charged with the catalyst and (ii) a convection section, where heat is recovered from the flue gases, having a temperature higher than $800^{\circ} \mathrm{C}$, for preheating and superheating feed and steam.

The design of the radiant chamber differs from the conventional one for the heated length of the reformer tube which is around 3 meter, the tube metallurgy and the contained catalyst. In particular, it must be observed that, owing to the lower operating temperature relevant to the use of this innovative architecture, a low cost stainless steel instead of exotic and quite expensive material as HP25/35 chromium/ nickel alloy was employed.

The reformed gas product from the first reformer is cooled down at the temperature chosen for membrane module operation and enters the first separation module. A retentate, recycled to the second reformer stage and a mixture of $\mathrm{H}_{2}$ plus sweeping steam, are produced. The second reformer stage is cooled down from $650^{\circ} \mathrm{C}$ to the temperature chosen for membrane operation and routed to the second separation module. $\mathrm{H}_{2}$ from both modules are mixed together and sent to final cooling and condensate separation. Retentate from the second stage is sent to the flare. The pressure of both shell and permeate sides are controlled using a back pressure regulators. Both membrane modules are protected using a pressure relief regulator installed on the income lines. All the vent points are connected to main vent system and routed to the flare. Heat of reaction in both reforming steps is provided by two independent hot gas generators in order to set the reforming temperatures as required by the tests. 
The main parameters such as the temperatures and pressures before and after each reformer and separation step as well as the pressure drop along the catalytic tube were monitored respectively with K-type thermocouples and differential pressure sensors. A constant flow of the exhaust stream is sent through a cold trap maintained at fixed temperature $\left(0^{\circ} \mathrm{C}\right)$ to NDIR analyzers (Uras 14, $\mathrm{ABB}$ ) for real-time $\mathrm{CH}_{4}, \mathrm{CO}, \mathrm{CO}_{2}$ measurements, while the concentration of $\mathrm{H}_{2}$ was performed with a thermoconductivity analyser (Caldos 17, $\mathrm{ABB}$ ).

Three different membrane separators, $\mathrm{Pd}$ and $\mathrm{Pd} / \mathrm{Ag}$ based, able to work at high temperatures $\left(480^{\circ} \mathrm{C}\right.$ for $\mathrm{ECN}$ and Japanese membranes, $500^{\circ} \mathrm{C}$ for MRT), were planned for installation on the prototypal plant. Their main features are summarised in Table 1.

\begin{tabular}{|c|c|c|c|c|}
\hline DeveloperSubstrate/support & $\begin{array}{c}\text { Membrane selective } \\
\text { layer }\end{array}$ & $\begin{array}{c}\text { Thickness selective layer, } \\
\mu \mathrm{m}\end{array}$ & Geometry \\
\hline $\mathrm{ECN}$ & $\mathrm{Al}_{2} \mathrm{O}_{3}$ & $\mathrm{Pd}$ & $3-9$ & Tubular \\
\hline $\mathrm{MRT}$ & $\mathrm{SS}$ & $\mathrm{Pd} / \mathrm{Ag}$ & 25 & Planar \\
\hline Japanese & $\mathrm{Al}_{2} \mathrm{O}_{3}$ & $\mathrm{Pd} / \mathrm{Ag}$ & $2-3$ & Tubular \\
\hline
\end{tabular}

Table 1. Main characteristics of the employed membranes (De Falco et al., 2011a)

Figure 7 show the installed membrane modules. The relevant permeation surfaces (A) are also reported.
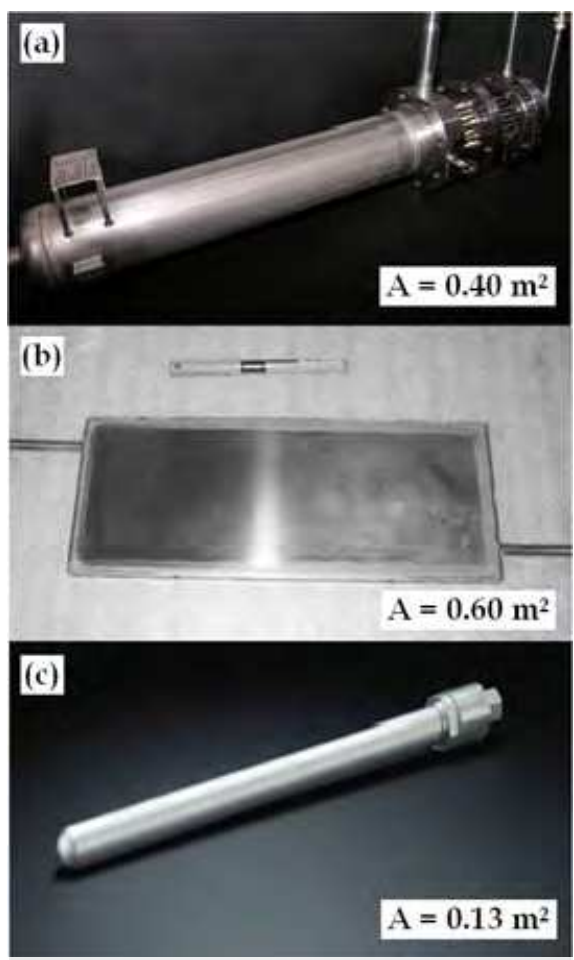

Fig. 7. ECN (a), MRT (b) and Japanese (c) membranes 
Another innovation of this work is represented by the catalyst employed for the catalytic activity tests. Typically, methane steam reforming catalysts for industrial production of hydrogen and synthesis gas are based on pellets shaped nickel/nickel oxide or cobalt compositions on refractory alumina or supports such as magnesium alumina spinel, often promoted with alkali or alkali-earth compounds to accelerate carbon removal (Faur Ghenciu, 2002). However, also noble metals based catalysts are often employed. Furthermore, the consideration that in the steam reforming process, the kinetics, and therefore the throughput, is limited by the rate at which the heat generated in external burners can be transferred to the catalytic bed where the endothermic reforming reactions take place, led for this plant to the choice of open cells foam structured catalysts, whose particular irregular network may greatly contribute to an intensification of heat and mass transfer along the catalytic bed in both axial and, more important, radial directions. In particular, the catalytic activity tests performed at the University of Salerno in collaboration with TKT in the framework of the above mentioned FISR project, on a pre-pilot scale autothermal reforming reactor showed how such structured supports, in particular when fabricated with high thermal conductivity materials, may contribute to an enhancement of heat transfer along the catalytic bed resulting in a flattening thermal profile (Palo, 2007; Ciambelli et al., 2007). More specifically, the catalyst loaded in the industrial steam reformer in Chieti Scalo was characterized by a commercial formulation Rh-Pt based (SR10, BASF) deposited on high thermal conductivity $\mathrm{SiC}$ open cells foams. Each cylindrical shaped element was $150 \mathrm{~mm}$ long with a diameter of $60 \mathrm{~mm}$ and twenty-one elements were loaded in each reformer.

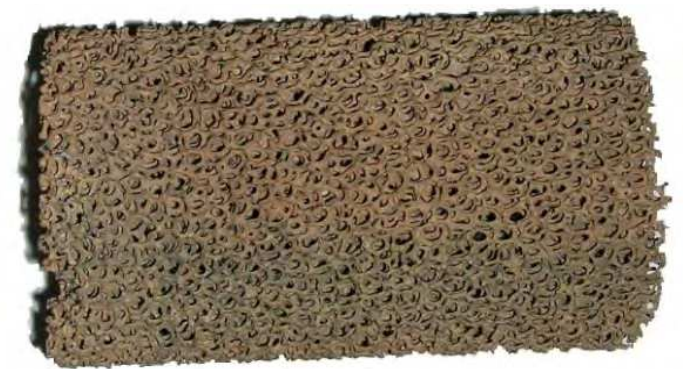

Fig. 8. Structured steam reforming catalyst

The catalytic activity tests were carried out in the following operating conditions: $3.8<\left(\mathrm{H}_{2} \mathrm{O} / \mathrm{CH}_{4}\right) \mathrm{w}<4.8,550^{\circ} \mathrm{C}<\mathrm{T}_{\text {reformer }}<680^{\circ} \mathrm{C}, \mathrm{P}=10$ barg, 4,300 $\mathrm{h}^{-1}<\mathrm{GHSV}<6,900 \mathrm{~h}^{-1}$ where the GHSV value is defined as the ratio between the total gaseous flow rate fed to the reactor (referred to $0^{\circ} \mathrm{C}$ and $1 \mathrm{~atm}$ ) and the total catalytic bed volume. For membrane characterization in terms of hydrogen flux and permeability, the following syngas composition was employed (Table 2).

\begin{tabular}{|c|c|c|c|c|}
\hline $\mathrm{H}_{2}, \mathrm{vol} \%$ & $\mathrm{CH}_{4}, \mathrm{vol} \%$ & $\mathrm{CO}_{2}, \mathrm{vol} \%$ & $\mathrm{CO}, \mathrm{vol} \%$ & $\mathrm{H}_{2} \mathrm{O}, \mathrm{vol} \%$ \\
\hline $24-30$ & $6-9$ & $6-9$ & $1-2$ & $54-59$ \\
\hline
\end{tabular}

Table 2. Typical syngas composition used for membranes characterization (De Falco et al., 2011a) 


\subsection{Plant performance}

The first preliminary catalytic activity tests without membrane integration were performed aiming to evaluate the effect of the main parameters, i.e. reformer outlet temperature, steam to carbon feed ratio and gas hourly space velocity, on $\mathrm{CH}_{4}$ conversion. The obtained results are reported in Figure 9.
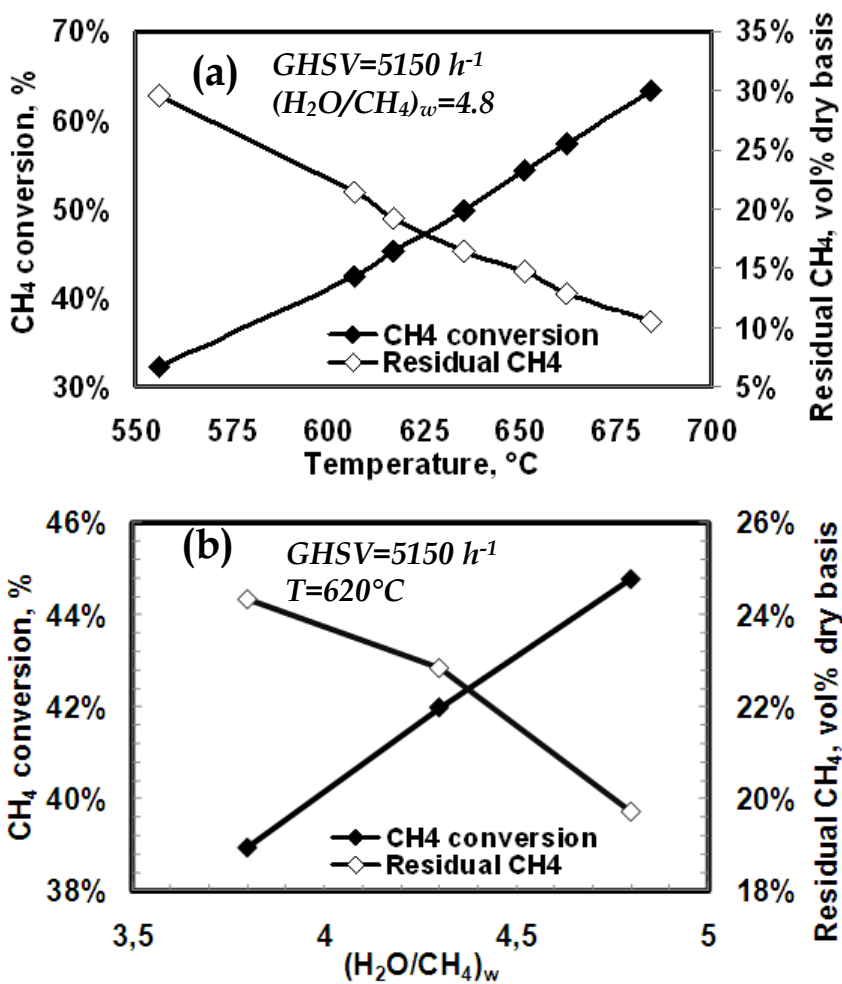

Fig. 9. Effect of reformer outlet temperature (a) and steam to carbon ratio (b) on $\mathrm{CH}_{4}$ conversion and residual $\mathrm{CH}_{4}$

It can be observed a decrease in the residual methane at the reactor outlet and a corresponding increase in methane conversion at increasing both the reformer outlet temperature (from $32 \%$ at $550^{\circ} \mathrm{C}$ to $64 \%$ at $680^{\circ} \mathrm{C}$ ) and the steam to carbon feed ratio (from $39 \%$ at $\mathrm{S} / \mathrm{C}=3.8$ to $44.8 \%$ at $\mathrm{S} / \mathrm{C}=4.8$ ). A detrimental effect was on the contrary noticed upon changing the GHSV value in the range 4,300-6,900 $\mathrm{h}^{-1}$ since a decrease in methane conversion from $48.7 \%$ to $46.5 \%$ was observed (De Falco et al., 2011a, De Falco et al., 2011b). However, in time on stream tests performed over $1000 \mathrm{~h}$, any catalyst deactivation occurred, as evidenced by stable methane conversion over the entire test period (De Falco et al., 2011a).

Membrane integration resulted in an enhanced overall plant performance. A comparison of methane conversion obtained in the absence or in the presence of membranes for hydrogen separation is reported in Figure 10 as a function of GHSV values. The results are collected 
over $200 \mathrm{~h}$ of operation at $10 \mathrm{barg}$, at a reformer outlet temperature ranging between 610$620^{\circ} \mathrm{C}$ and at a steam to carbon ratio of 4.8 (De Falco et al., 2011a).

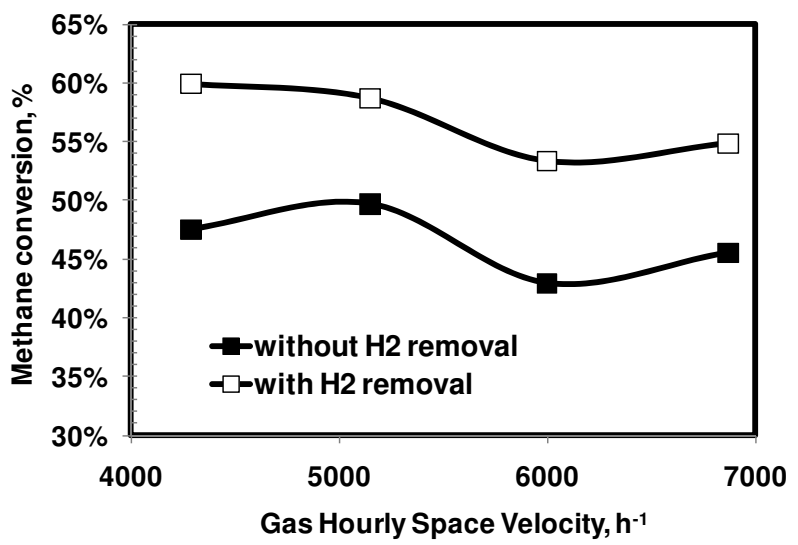

Fig. 10. Effect of hydrogen removal on plant performance at changing the gas hourly space velocity

All these catalytic activity tests enabled for a membranes permeability characterization. In particular, by assuming the Arrhenius law for the dependence of permeability from temperature and the Sievert-Fick's law for hydrogen flux expression (Ockwig and Nenoff, 2007), the following results were obtained for the tested three membranes (Table 3, De Falco et al., 2011a):

\begin{tabular}{|c|c|c|c|}
\hline Membrane & $\begin{array}{c}\text { Pre-exponential factor, } \\
\mathrm{kmol} /(\mathrm{m} \mathrm{h} \mathrm{kPa} 0.5)\end{array}$ & $\begin{array}{c}\text { Activation energy, } \\
\mathrm{kJ} / \mathrm{mol}\end{array}$ & $\begin{array}{c}\text { Permeability at } 450^{\circ} \mathrm{C}, \\
\mathrm{kmol} /(\mathrm{m} \mathrm{h} \mathrm{kPa} 0.5)\end{array}$ \\
\hline ECN & $1.72 \times 10^{-1}$ & 77.0 & $4.67 \times 10^{-7}$ \\
\hline MRT & $5.75 \times 10^{-4}$ & 35.3 & $1.61 \times 10^{-6}$ \\
\hline Japanese & $9.31 \times 10^{-2}$ & 80.4 & $1.44 \times 10^{-7}$ \\
\hline
\end{tabular}

Table 3. Permeability membranes characterisation results (De Falco et al., 2011a)

Furthermore, starting from permeability expression above reported, for ECN membrane several parametric studies were performed, enabling to predict the overall $\mathrm{CH}_{4}$ conversion with both: (i) a larger membrane surface (De Falco et al., accepted for publication) and (ii) a higher membrane thickness as parameters. In both cases, the experimental operating conditions were the following: $\mathrm{P}_{\text {ref }}=10$ barg, $\left(\mathrm{H}_{2} \mathrm{O} / \mathrm{CH}_{4}\right) \mathrm{w}=4.8, \mathrm{P}_{\text {perm }}=0.4 \mathrm{barg}, \mathrm{T}_{\text {mem }}=430^{\circ} \mathrm{C}$. The $\mathrm{CH}_{4}$ conversion evaluation was carried out by commercial process flow modeling (PRO II) integrated with a subroutine to simulate membrane behaviour.

The first case was more specifically developed by assuming in the calculations the same permeance of $30 \mathrm{Nm}^{3} / \mathrm{m}^{2} \mathrm{~h}$ bar ${ }^{0.5}$ obtained at $430^{\circ} \mathrm{C}$. The $\mathrm{CH}_{4}$ conversion was found to be enhanced with an increase in the reforming temperature and membrane area. In particular, the membrane area can be increased to achieve the same conversion at lower reformer temperature (methane conversion of $60 \%$ can be achieved at $603^{\circ} \mathrm{C}$ with $\mathrm{A}=1.2 \mathrm{~m}^{2}$, at $623^{\circ} \mathrm{C}$ with $\mathrm{A}=0.4 \mathrm{~m}^{2}$ ). Methane conversion increases more slowly when the membrane area 
exceeds $0.8 \mathrm{~m}^{2}$. By comparing such data with those obtained in the absence of membrane, it was possible to evaluate the conversion increase with such open architecture. At $620^{\circ} \mathrm{C}$ such increase ranges from 11 to 19 point percent respectively, with a membrane surface of $0.4 \mathrm{~m}^{2}$ and $0.8 \mathrm{~m}^{2}$.

In the second case, the membrane permeance was extrapolated at different selective layer thicknesses ranging between 2.5 and 100 micron. The results are reported in Figure 11, as well as those obtained from literature review.

Obviously, the thickness of the separation layer greatly affects the membrane permeance which resulted lowered from $2.12 \times 10^{-4}$ to $5.3 \times 10^{-6}$ at $350^{\circ} \mathrm{C}$ and from $7.85 \times 10^{-3}$ to $1.96 \times 10^{-}$ 4 at $550^{\circ} \mathrm{C}$ by increasing the thickness of the separation layer from 2.5 to 100 micron. The obtained results pointed out on the continuous industrial efforts aiming to develop composite membrane made of a very thin Pd layer. It is worth nothing that reducing the selective layer thickness allows membrane cost to be decreased (decreasing the Pd thickness by a factor two reduces the total Pd cost by a factor four) and increasing the hydrogen flux, which is in inverse proportion with the film thickness. On the other side, a too high decrease in the selective film thickness may result in an excessive embrittlement of the membrane which becomes too mechanically fragile for the condition of high temperature catalytic processes.

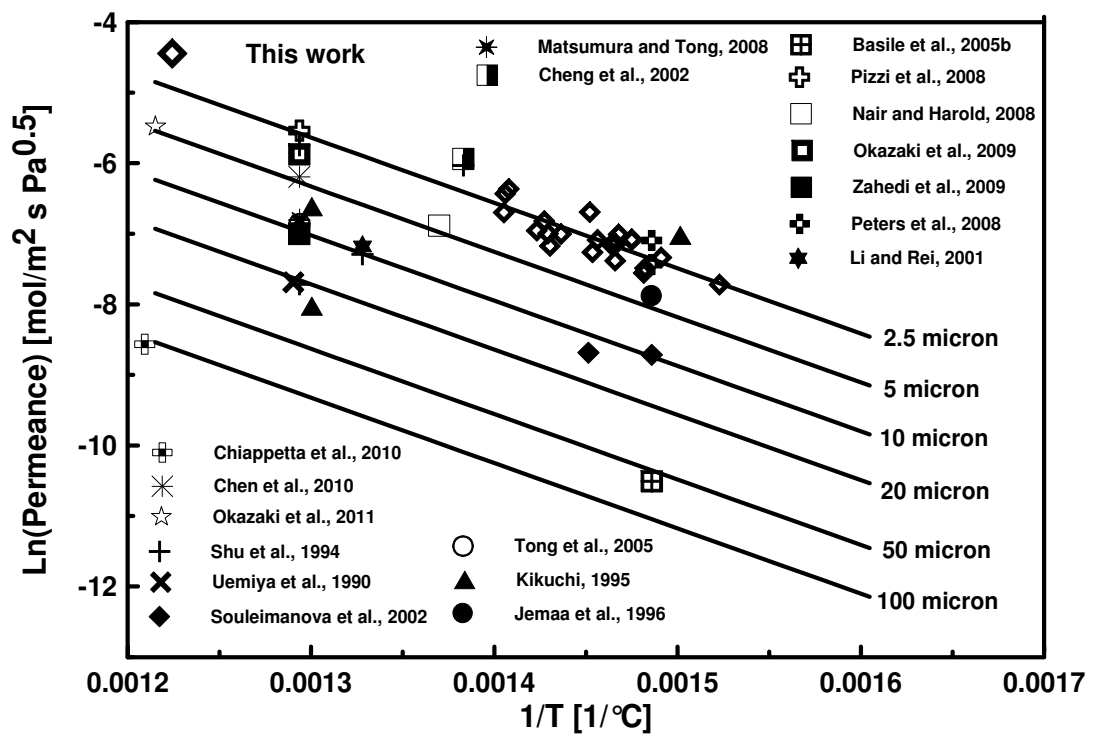

Fig. 11. Effect of membrane thickness on ECN membrane permeance

In terms of $\mathrm{CH}_{4}$ conversion, the influence of the selective layer thickness is reported in Figure 12, even at lower value than those reported in Figure 11.

At each operating temperature investigated, the decrease of membrane thickness resulted in higher methane conversion. In particular, at $630^{\circ} \mathrm{C}$, a reduction of membrane thickness from 2.5 micron to 0.5 micron may enhance methane conversion of $10 \%$ due to the higher hydrogen removal. It is interesting to note that thickness thinner than 0.5 micron have no more significant effect on the overall performance. Such a thickness could be considered as 
the technological limit to be overcome. Globally it is possible to reach $\mathrm{CH}_{4}$ conversion higher than $90 \%$ with a permeated $\mathrm{H}_{2}$ flux of $300 \mathrm{Nm}^{3} / \mathrm{m}^{2} \mathrm{~h}$ bar. 0.5 .

The achievement of this goal shows the industrial feasibility of this option up to now demonstrated only on a laboratory scale, even if the last gap to be overcome for the technology commercialization is represented by the optimization of membrane preparation procedure with enhancement of their stability.

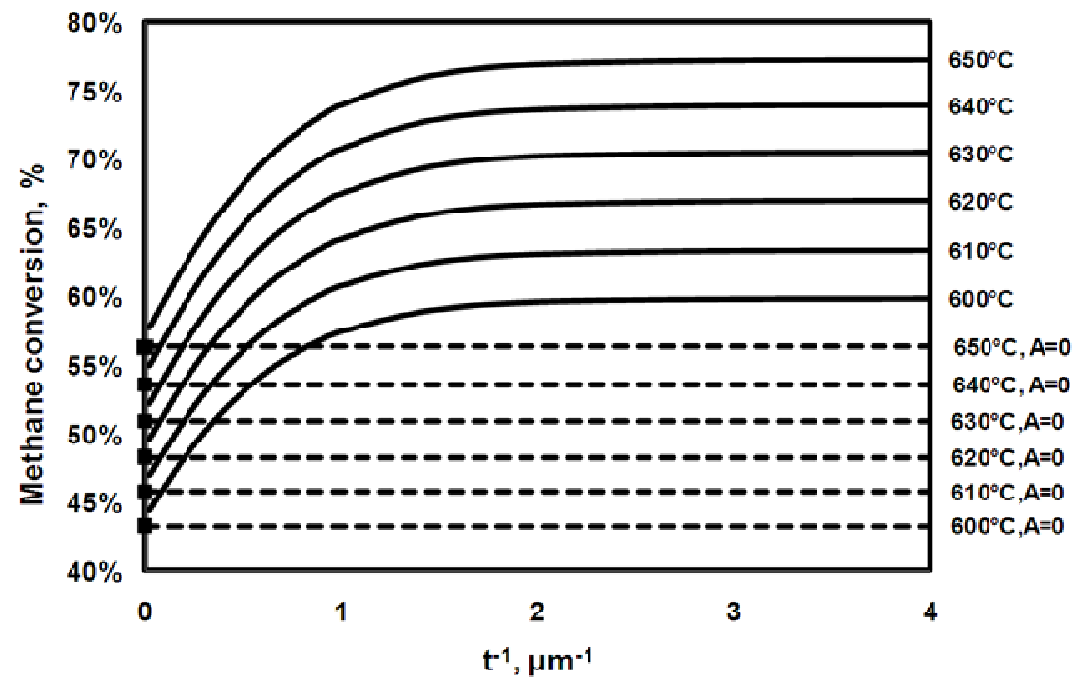

Fig. 12. Effect of membrane thickness on $\mathrm{CH}_{4}$ conversion with ECN membrane

\subsection{Application to nuclear power}

In order to sustain the global endothermic steam reforming reaction, a part of the methane feedstock must be burned in a fired heater. To reduce this consumption, purge gas coming from PSA unit or retentate from the membrane separation unit have to be burned. The calorific value of these streams is a function of composition and consequently of the achieved conversion. A self-balance of heat exits with a fixed external natural gas supply, at an appropriate level of feed conversion. Therefore, conversion should not exceed the point closing the heat balance (around 60\%).

Furthermore, it must be considered that owing to the high process temperature, the thermal efficiency of this process is about 65 to $75 \%$. Also, a substantial amount of greenhouse gases (GHG) is emitted as $\mathrm{CO}_{2}$ produced along with hydrogen. Moreover, carbon dioxide is also emitted during the burning of a part of methane feedstock in order to sustain the global endothermic balance of the steam reforming reaction. In total, a typical steam reforming process emits up to $8.5-12 \mathrm{~kg} \mathrm{CO} 2$ per $1 \mathrm{~kg} \mathrm{H}_{2}$. To prevent the emitted $\mathrm{CO}_{2}$ to be released into the atmosphere, it needs to be captured. Presently, all commercial $\mathrm{CO}_{2}$ capture plants use processes based on chemical absorption with amine solvents as monoethanolamine (MEA) or (methyldiethanolamine) MDEA, which is a considerably energy intensive step and thus is unfavourable to the overall process energy efficiency.

Therefore, a higher methane conversion is required to reduce the carbon dioxide emission per unit of hydrogen produced. This could be achieved by using heat from an external 
source such as a high temperature nuclear reactor. Replacing the burning of natural gas by nuclear heat allows avoiding, at least partially, all the $\mathrm{CO}_{2}$ production related to fuel burning (De Falco et al. accepted for publication, Iaquaniello and Salladini, 2011).

High temperature helium-cooled reactors are the best understood nuclear technology that can supply high temperature heat for thermal processes for producing hydrogen. Nuclear reactor designers became interested in high-temperature helium-cooled reactors more than 40 years ago because of the new possibility for heating the helium at the reactor exit up to $1000^{\circ} \mathrm{C}$ and the enhanced safety of the reactor (Mitenkov et al., 2004).

The synergistic production of hydrogen using fossil fuels and nuclear energy is considered to be extremely advantageous, especially when performed through a recirculation-type membrane reformer (Hori et al., 2005).

In particular, even assuming an idealistic case, in which all the heat generated by combustion of hydrocarbon is used for the heat of endothermic reaction of steam reforming as well as a portion of the heat released by exothermic water gas shift reaction, the consumption of methane for the nuclear-heated steam reforming reaction is $17 \%$ less of that of the conventional steam reforming reaction for producing the same amount of hydrogen. In the actual case of conventional steam reforming as the heat utilization and the reaction yield are limited, the efficiency of the process will be around $80 \%$, that is $2.7 \mathrm{~mol}$ of hydrogen produced from $1 \mathrm{~mol}$ of methane feed. In the case of nuclear-heated recirculationtype membrane reformer, as no methane is consumed for combustion and the yield of hydrogen is nearly stoichiometric, the nuclear-heated SMR reaction will produce 4 mol of hydrogen from $1 \mathrm{~mol}$ of methane. Therefore, this process scheme will save about $30 \%$ natural gas consumption, or reduce $30 \%$ carbon dioxide emission, comparing with traditional process (Hori et al., 2005). Furthermore, typical merits of this process are: (i) nuclear heat supply at medium temperature around $550^{\circ} \mathrm{C}$, (ii) compact plant size and membrane area for hydrogen production, (iii) efficient conversion of a feed fossil fuel, (iv) appreciable reduction of carbon dioxide emission, (v) high purity hydrogen without any additional process and (vi) ease of separating carbon dioxide for future sequestration requirements.

Figure 13 reports a plant configuration of hydrogen and pressurized $\mathrm{CO}_{2}$ production coupled with a nuclear reactor cooled by He.

Natural gas is compressed, heated and mixed with hydrogen recycle before entering the hydro desulphurizer reactor (HDS). The desulphurised feed is mixed with steam, preheated in the convective section CC-01 and fed to the first reforming step (R-01). The reformed gas reaction mixture at $600-650^{\circ} \mathrm{C}$ is cooled down to a proper temperature for membrane separation, i.e. $450-470^{\circ} \mathrm{C}$, before entering the first separation module. Sweeping steam is sent to the permeate side of the membrane to reduce the hydrogen partial pressure with a consequent improvement of hydrogen permeation. The permeate side stream, composed of hydrogen and sweeping steam, is sent to the cooling and water condensing section. The retentate from the first membrane module is sent to the second reforming rector (R-02) for further methane conversion.

A part of the final retentate is recycled to the post combustion chamber. The hydrogen permeated is separated from water stream by condensation and routed to a compression section and to a PSA unit where final purification is carried out. A portion of the $\mathrm{H} 2$ produced is recycled to the feed where it is needed to keep the catalyst in the first part of the reformer in an active state. 


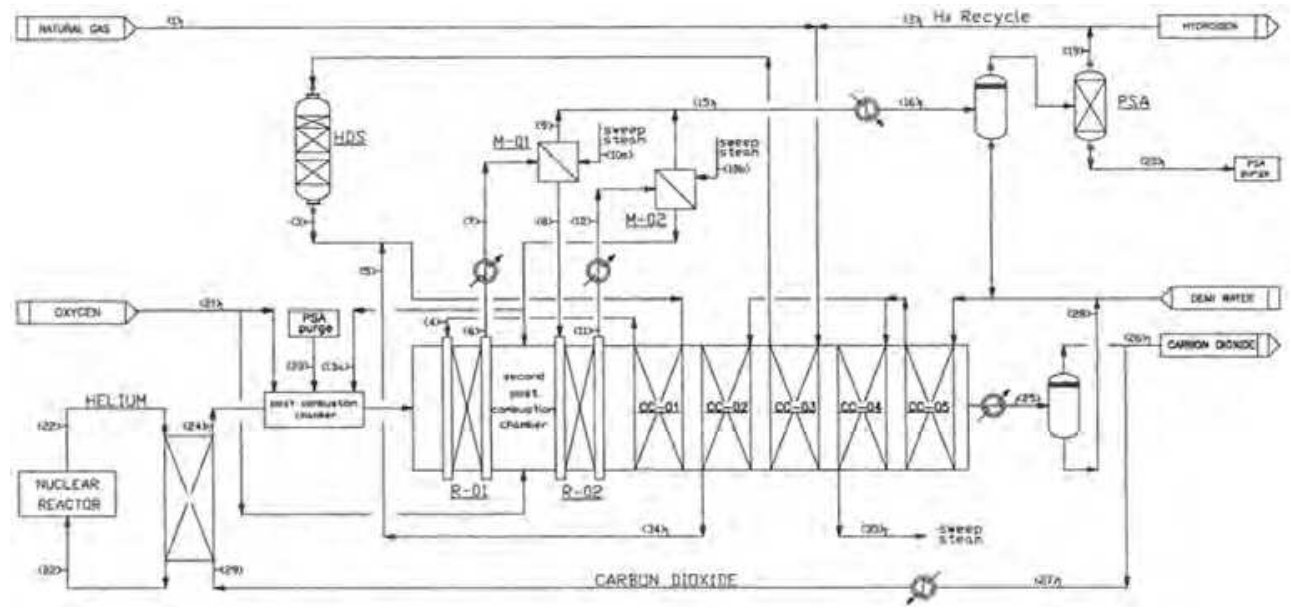

Fig. 13. Process scheme of hydrogen and pressurised $\mathrm{CO}_{2}$ production coupled with a nuclear reactor cooled by $\mathrm{He}$

Thermal fluid used to transfer thermal energy from the nuclear cycle to reforming reactors is $\mathrm{CO}_{2}$ circulating within a closed loop. $\mathrm{CO}_{2}$ is firstly heated up by the heat exchange medium of a nuclear plant in an intermediate heat exchanger. Its temperature is further increased in the post-combustion chamber where all the purge gas from the PSA unit together with a portion of retentate are burned to achieve a correct temperature. Thus, the thermal fluid is a pressurized mixture of only $\mathrm{CO}_{2}$ and $\mathrm{H}_{2} \mathrm{O}$ due to the use of pure oxygen in post combustion. After heat recovery, thermal fluid is cooled down to separate water from $\mathrm{CO}_{2}$. The latter is recycled back to the nuclear reactor while a portion, corresponding to that produced in post combustion, is removed from the closed loop. Water, produced in post combustion, can be recycled to the process. This kind of separation is much simpler and less energy intensive than a traditional physical absorption process with amine solutions. Moreover, providing the reformer duty through pressurized carbon dioxide instead of, e.g., air allows to achieve a higher heat transfer coefficient due to the higher heat capacity and gas emissivity.

By applying the proposed scheme, hydrogen and pressurized carbon dioxide are produced with a nuclear heat source and with a reduced carbon dioxide emission. In this way, the major portion of the heat required for the steam reforming reaction is not provided by the combustion of fresh hydrocarbons but is supplied from a separate unit without carbon dioxide emissions.

The scheme presented in Figure 13 realises a feed conversion of $90 \%$ with a carbon dioxide production equal to $6 \mathrm{kgCO}_{2} / \mathrm{kgH}_{2}$ corresponding to $0.55 \mathrm{kgCO}_{2} / \mathrm{Nm}^{3} \mathrm{H}_{2}$. From the energy point of view, using a RMM architecture allows to produce hydrogen with a higher overall energy efficiency. The reduced reforming temperature achievable only by membrane application, allows performing the exothermic water gas shift reaction simultaneously with the endothermic steam reforming reaction reducing in this way the net heat duty. The proposed scheme achieves a hydrogen production with an overall energy efficiency of more than $85 \%$. Such a scheme could be also considered a first step in producing ammonia and urea by reacting ammonia with $\mathrm{CO}_{2}$ recovered (Figure 14). 


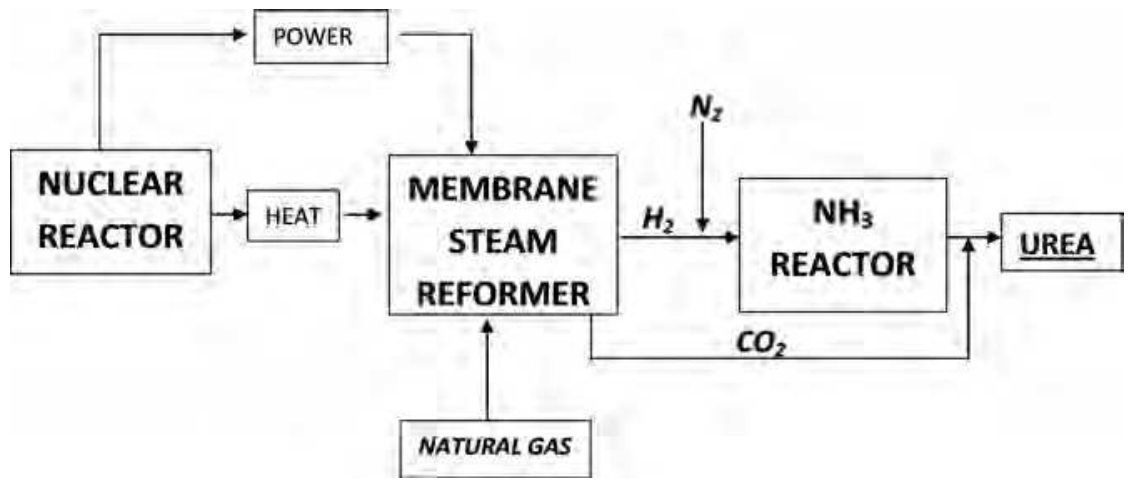

Fig. 14. Process scheme for urea production coupling a membrane steam reformer with a nuclear reactor

\section{Economic analysis}

An economic analysis was performed at first focusing attention on membrane production costs, further the analysis was extended to the coupled process scheme proposed in the previous section.

In order to tackle this issue and to be able to forecast a production cost for thin Pd-based membranes, it is important to introduce the concept of "economics of learning" in understanding the behaviour of all added costs of membranes as cumulative production volume increased. Such economics of learning or law of the experience may be expressed more precisely in an algebraic form (7):

$$
c_{n}=c_{1} n^{-a}
$$

where $c_{1}$ is the cost of the unit production (square meter of membrane for instance), $c_{n}$ is the cost of the $\mathrm{n}^{\text {th }}$ unit of production, $\mathrm{n}$ is the cumulative volume of production, and a is the elasticity of cost with regard to output.

Graphically, the experience curve is characterized by a progressively declining gradient, which, when translated into logarithms, is linear. The size of experience effect is measured by the proportion by which costs are reduced with subsequent doublings of aggregate production.

Constructing an experience curve is a simple matter once the data are available. Of course for the Pd-based or ceramic membrane such dates are limited to minimal surface (less than 1 $\mathrm{m}^{2}$ ), which can, however, be used as starting point of the curve. The other issue associated with drawing an experience curve is that cost and production data must be related to a "standard product", which is not the case due to the fact that in the membrane technology no standard is yet emerged and there is a lot of discussion on the membrane composition and preparation method, supporting matrix and other mechanical and construction details. It is, however, a fact that costs decline systematically with increases in cumulative output. The assumptions made in the following are that $c_{1}=50,000 €$ and $a=0.25$, where $c_{1}$ value derived by Tecnimont-KT recent experience in building a pilot unit, meanwhile the " $\mathrm{a}$ " factor was assumed as average value typically between 20 and $30 \%$.

Using such a data is possible to forecast the cost for $\mathrm{m}^{2}$ of membrane module versus the cumulative value of production, expressed in terms of $\mathrm{m}^{2}$. Table 4 shows such data. 


\begin{tabular}{|c|c|}
\hline Cumulated production $\mathrm{m}^{2}$ & $€$ cost per $\mathrm{m}^{2}$ \\
\hline 1,000 & 8,900 \\
\hline 10,000 & 5,000 \\
\hline 100,000 & 2,800 \\
\hline $1,000,000$ & 1,600 \\
\hline $10,000,000$ & 900 \\
\hline
\end{tabular}

Table 4. Cost per $\mathrm{m}^{2}$ of membrane module versus cumulated production

From the drawn experience curve, some implications for the membranes market business strategy can be extracted. The first and more important question to answer is when a $1,000,000 \mathrm{~m}^{2}$ of membrane module cumulative production could be reached in order to have a unit cost around $1.600 €$ per $\mathrm{m}^{2}$ of membrane.

In order to answer such a question, further considerations need to be developed, to relate surface to membrane module to the $\mathrm{H}^{2}$ production and to the introduction of such a new technology in the market.

On previous published data, Iaquaniello et al. (2008) were calculating for a open membrane reactor architecture a surface of $1,000 \mathrm{~m}^{2}$ for an installed capacity of $10,000 \mathrm{Nm}^{3} / \mathrm{h}$ of hydrogen. The envisaged installed capacity in the hydrogen market is today around $1 \mathrm{MM}$ $\mathrm{Nm}^{3} / \mathrm{h}$ of capacity per year, which translated into a production of $100,000 \mathrm{~m}^{2}$ of membrane year, once the new technology will supersede the conventional one.

To derive the rate of membranes technology introduction in the market a Volterra equation was considered (8):

$$
\mathrm{x}=\mathrm{A} /\left(1+\mathrm{e}^{(\mathrm{Bx})}\right)+\mathrm{C}
$$

where $\mathrm{A}, \mathrm{B}, \mathrm{C}$ are constants and $\mathrm{x}$ is the cumulative production.

Such equation, also called "S logistic curve" is used to describe a process with a low growth which accelerate with time to seem an exponential growth. A 10-year period (2012-2022) is considered to achieve 50\% substitution in the conventional market starting from 2012, which roughly implies that over the next decade half a million of square meters of membranes modules could be produced. With such cumulative production around year 2020, the membrane cost per $\mathrm{m}^{2}$ could reach the target of $1.600 €$ per $\mathrm{m}^{2}$ and the overall market will have a size of 1 billion of $€$ per year.

Figure 14 represents the cumulative production coupled to the " $S$ " curve.

The approach used to determine the growth of the membranes market, together with the cumulative production does not, however, identify the real factors that determine its dynamics. As matter of fact, the experience curve combines four sources of costs reduction: learning, economics of scale, process innovation, and improved production design.

Economics of scale, conventionally associated with manufacturing operations, is probably the most important of these costs drivers and exists wherever as the scale of production increases unit costs fall. A plant capacity has then an economic sense if a minimum efficiency plant capacity is reached.

This will imply that to reach the required reduction in the membrane cost, not only a few specialized technologies must emerge, but the production market will be concentrated in few highly specialized production plants.

Regarding the proposed process scheme coupling a membrane based steam reformer with a nuclear reactor, a preliminary investigation was carried out under the basic assumption that the cost of electric power from nuclear source is $0.03 € / \mathrm{kWh}$ (Romanello et al., 2006). Thus, in 
order to produce $1000 \mathrm{kWh}$ the total costs amount is $30 €$. Considering an efficiency equal to around $34 \%$, so that $3000 \mathrm{kWh}_{\text {th }}$ (or $2580000 \mathrm{kcal}$ ) should be produced to obtain our power target, this will translate into a cost of $12 € / M M k c a l$ against more than $30 €$ for heat produced from natural gas. The variable costs of producing $\mathrm{H}_{2}$ are then reduced of more than $20 \%$ without considering the beneficial effects of reduced $\mathrm{CO}_{2}$ emissions in the atmosphere.

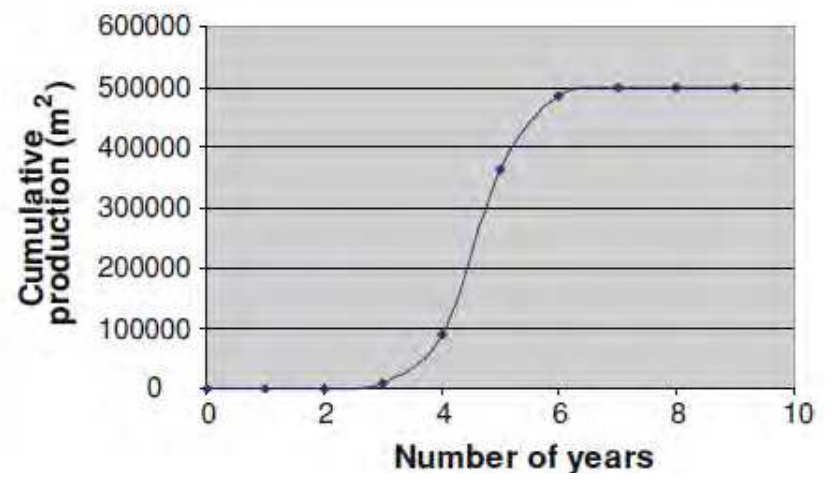

Fig. 15. Cumulative production coupled to the "S" curve

Compared to the thermochemical processes, hydrogen production by nuclear-heated steam reforming of natural gas is considered to be much closer to commercialization and is viewed as an intermediate step to nuclear-driven hydrogen production from water.

Alternatively such process could be modified to produce urea without any additional $\mathrm{CO}_{2}$ emissions.

\section{Conclusions and future perspectives}

Membrane reforming with recirculation of reaction products in closed loop configuration is a particularly promising nuclear application, even if one of the last gap to be overcome for the technology commercialization of membrane reformers is represented by the optimization of membrane preparation procedure with enhancement of their stability. Because the nuclear heat is needed at below $600^{\circ} \mathrm{C}$, it employs a compact membrane and reformer, and gives efficient conversion of the hydrocarbon feed and high-purity hydrogen without additional processing. With all these benefits, the synergistic blending of fossil fuels and nuclear energy to produce hydrogen, ammonia and urea, can be an effective solution for the world until large-scale thermochemical water splitting processes, which may benefits from economy of scale, are available. For both the fossil fuels industry and the nuclear industry, this approach offers a viable symbiotic strategy with the minimum of impact on resources, the environment and the economy.

\section{Acknowledgment}

The pre-industrial natural gas steam reforming RMM plant was developed within the framework of the project "Pure hydrogen from natural gas reforming up to total conversion obtained by integrating chemical reaction and membrane separation", financially supported by 
MIUR ( FISR DM 17/12/2002)-Italy. The authors are grateful to Prof. Luigi Marrelli and Prof. Diego Barba for their support.

\section{References}

Basile, A.; Gallucci, F. \& Paturzo, L. (2005a). A dense Pd/ Ag membrane reactor for methanol steam reforming: Experimental study. Catalysis Today, Vol. 104, No. 2-4, (June 2005), pp. 244-250, ISSN 0920-5861.

Basile, A.; Gallucci, F. \& Paturzo, L. (2005b). Hydrogen production from methanol by oxidative steam reforming carried out in a membrane reactor. Catalysis Today, Vol. 104, No. 2-4, (June 2005), pp. 251-259, ISSN 0920-5861.

Chen, W. ; Hu, X.; Wang, R. \& Huang, Y. (2010). On the assembling of Pd/ceramic composite membranes for hydrogen separation. Separation and Purification Technology Vol. 72, No. 1, (March 2010), pp. 92-97, ISSN 1383-5866.

Cheng, Y.S.; Pena, M. ; A., Fierro J. L. ; Hui, D.C.W. \& Yeung, K.L. (2002). Performance of alumina, zeolite, palladium, Pd-Ag alloy membranes for hydrogen separation from towngas mixture. Journal of Membrane Science, Vol. 204, No. 1-2, (July 2002), pp. 329340, ISSN 0376-7388.

Chiappetta, G.; Barbieri, G. \& Drioli, E. (2010). Pd/Ag based membranes reactors on small scale: assessment of the feed pressure and design parameters effect on the performance. Chemical Engineering and Processing: Process Intensification, Vol. 49, No. 7, (July 2010), pp. 722-731, ISSN 0255-2701.

Ciambelli, P.; Palma, V.; Palo, E.; Iaquaniello, G.; Mangiapane, A. \& Cavallero, P. (2007). Energy sustainable development through methane autothermal reforming for hydrogen production. AIDIC Conference Series, Vol. 8, pp. 67-76, ISBN 0390-2358.

De Falco, M. ; Di Paola, L. ; Marrelli, L. \& Nardella, P. (2007). Simulation of large-scale membrane reformers by a two-dimensional model. Chemical Engineering Journal, Vol. 128, No. 2-3, (April 2007), pp. 115-125, ISSN 1385-8947.

De Falco, M. ; Iaquaniello, G. \& Salladini, A. (2011a). Experimental tests on steam reforming of natural gas in a reformer and membrane modules (RMM) plant. Journal of Membrane Science, Vol. 368, No. 1-2, (February 2011), pp. 264 - 274, ISSN 0376-7388.

De Falco, M. ; Marrelli, L. \& Iaquaniello, G. (2011b). Membrane Reactors for Hydrogen Production Processes. Springer Ed., ISBN 978-0-85729-150-9.

De Falco, M. ; Salladini, A. \& Iaquaniello, G. (accepted for publication). Reformer and membrane modules (RMM) for methane conversion : experimental assessment and perspectives of said innovative architecture. ChemSusChem, ISSN 1864-564X.

Dittmeyer, R. ; Höllein, V. \& Daub, K. (2001). Membrane reactors for hydrogenation and dehydrogenation processes based on supported palladium. Journal of Molecular Catalysis A: Chemical, Vol. 173, No. 1-2, (September 2001), pp. 135-184, ISSN 13811169.

Dybkjaer, I. (1995). Tubular reforming and autothermal reforming of natural gas - an overview of available processes. Fuel Processing Technology, Vol. 42, No. 2-3, (April 1995), pp. 85-107, ISSN 0378-3820.

Faur Ghenciu, A. (2002). Review of fuel processing catalysts for hydrogen production in PEM fuel cell systems. Current Opinion in Solid State \& Materials Science, Vol. 6, No. 5, (October 2002), pp. 389-399, ISSN 1359-0286. 
Hori, M.; Matsui, K.; Tashimo, M.; Yasuda, I. (2005). Synergistic hydrogen production by nuclear-heated steam reforming of fossil fuels. Progress in Nuclear Energy, Vol. 47, No. 1-4, (December 2005), pp. 519-526, ISSN 0149-1970.

Iaquaniello, G.; Giacobbe, F.; Morico, B.; Cosenza, S.; Farace, A. (2008). Membrane reforming in converting natural gas to hydrogen: Production costs, Part II. International Journal of Hydrogen Energy, Vol. 33, No. 22, (November 2008), pp. 6595-6601, ISSN 0360-3199.

Iaquaniello, G. \& Salladini, A. (2011). Method for hydrogen production. European Patent Application EP11150491.

Jemaa, N. ; Shu, J. ; Kaliaguine, S. \& Grandjean, B. (1996). Thin palladium film formation on shot peening modified porous stainless steel substrates. Industrial $\mathcal{E}$ Engineering Chemistry Research, Vol. 35, No. 3, (March 1996), pp. 973-977, ISSN 0888-5885.

Kikuchi, E. (1995). Palladium/ceramic membranes for selective hydrogen permeation and their application to membrane reactor. Catalysis Today, Vol. 25, No. 3-4, (August 1995), pp. 333-337, ISSN 0920-5861.

Li, Y.M. \& Rei, M.H. (2001). Separation of hydrogen from the gas mixture out of catalytic reformer by using supported palladium membrane. Separation and Purification Technology, Vol. 25, No. 1-3, (October 2001), pp. 87-95, ISSN 1383-5866.

Matsumura, Y. \& Tong, J. (2008). Methane steam reforming in hydrogen-permeable membrane reactor for pure hydrogen production. Topics in Catalysis, Vol. 51, No. 14, (October 2008), pp. 123-132, ISSN 1022-5528.

Mendes, D. ; Mendes, A. ; Madeira, L. M. ; Iulianelli, A. ; Sousa, J. M. \& Basile, A. (2010). The Water-Gas Shift Reaction: From Conventional Catalytic Systems to Pd-based Membrane Reactors - a Review. Asian-Pacific Journal of Chemical Engineering on Membrane Reactors, Vol. 5, No. 1, (August 2009), pp. 111-137, ISSN 1932-2143.

Mitenkov, F.M. ; Kodochigov, N.G. ; Vasyaev, A.V. ; Golovko, V.F. ; Ponomarev-Stepnoi, N.N. ; Kukharkin, N.E. \& Stolyarevskii, A.Ya. (2004). High-temperature gas-cooled reactors-energy source for industrial production of hydrogen. Atomic Energy, Vol. 97, No. 6, (December 2004), pp. 829-840, ISSN 1063-4258.

Mulder, M. (1996). Basic Principles of Membrane Technology. Kluwer Academic: Dordrecht pp. 564.

Nair, B. K. R \& Harold, M. P. (2008). Experiments and modeling of transport in composite $\mathrm{Pd}$ and Pd/Ag coated alumina hollow fibers. Journal of Membrane Science, Vol. 311, No. 1-2, pp. 53-67, ISSN 0376-7388.

Ockwig, N.W. \& Nenoff T.M. (2007). Membranes for hydrogen separation. Chemical Reviews, Vol. 107, No. 10, (October 2007), pp. 4078-4140, ISSN 0009-2665.

Okazaki, J. ; Ikeda, T. ; Pacheco Tanaka, D.A. \& Sato, K. (2011). An investigation of thermal stability of thin palladium-silver alloy membranes for high temperature hydrogen separation. Journal of Membrane Science, Vol. 366, No. 1-2, pp. 212-219, ISSN 03767388.

Okazaki, J. ; Ikeda, T. ; Pacheco Tanaka, D. A. ; Suzuki, T. M. \& Mizukami F. (2009). In situ high-temperature X-ray diffraction study of thin palladium-a-alumina composite membranes and their hydrogen permeation properties. Journal of Membrane Science, Vol. 335, No. 1-2, pp. 126-132, ISSN 0376-7388.

Palo, E. (2007). Structured catalysts for hydrogen production by methane autothermal reforming. PhD Thesis, University of Salerno. 
Peters, T. A.; Stange, M.; Klette, H. \& Bredesen R. (2008). High pressure performance of thin $\mathrm{Pd}-23 \% \mathrm{Ag} /$ stainless steel composite membranes in water gas shift gas mixture: influence of dilution, mass transfer and surface effects on hydrogen flux. Journal of Membrane Science, Vol. 316, No. 1-2, pp. 119-127, ISSN 0376-7388.

Pizzi, D.; Worth, R. ; Baschetti, M. G. ; Sarti G. C. \& Noda K. (2008). Hydrogen permeability of $2.5 \mu \mathrm{m}$ palladium-silver membranes deposited on ceramic supports. Journal of Membrane Science, Vol. 325, No. 1, pp. 446-453, ISSN 0376-7388.

Romanello, V.; Lomonaco, G.; Cerullo, N. (2006). I veri costi dell'energia nucleare. NT1127(2006). Università di Pisa.

Sanchez Marcano, J.G. \& Tsotsis, T.T. (2002). Catalytic membranes and membrane reactors. Wiley-VCH Verlag, Weinheim.

Shu, J.; Grandjean, B. \& Kaliaguine, S. (1994). Methane steam reforming in asymmetric Pdand Pd-Ag/porous SS membrane reactors. Applied Catalysis A : General, Vol. 119, No. 2, (November 1994), pp. 305-325, ISSN 0926-860X.

Souleimanova, R.S.; Mukastan, A.S. \& Varma, A. (2002). Pd membranes formed by electroless plating with osmosis: $\mathrm{H}_{2}$ permeation studies. AIChE Journal, Vol. 48, No. 2, (February 2002), pp. 262-268, ISSN 1547-5905.

Tong, J.; Matsumura, Y. ; Suda, H. \& Haraya, K. (2005). Thin and dense Pd/CeO $/ \mathrm{CMSS}$ composite membrane for hydrogen separation and steam reforming of methane. Separation and Purification Technology, Vol. 46, No. 1-2, (November 2005), pp. 1-10, ISSN 1383-5866.

Uemiya, S.; Sato, N.; Ando, H. ; Matsuda, T. \& Kikuchi, E. (1990). Steam reforming of methane in a hydrogen-permeable membrane reactor. Applied Catalysis, Vol. 67, pp. 223-230.

Xia, Y.; Lu, Y.; Kamata, K.; Gates, B. \& Yin, Y. (2003). Macroporous materials containing three-dimensionally periodic structures. Chemistry of Nanostructured Materials (Ed.: Yang, P.), World Scientific 69-100.

Zahedi, M.; Afra, B.; Dehghani-Mobarake, M. \& Bahmani, M. (2009). Preparation of a Pd membrane on a $\mathrm{WO}_{3}$ modified Porouys Stailess steel for hydrogen separation. Journal of Membrane Science, Vol. 333, No. 1-2, (May 2009), pp. 45-49, ISSN 03767388 . 


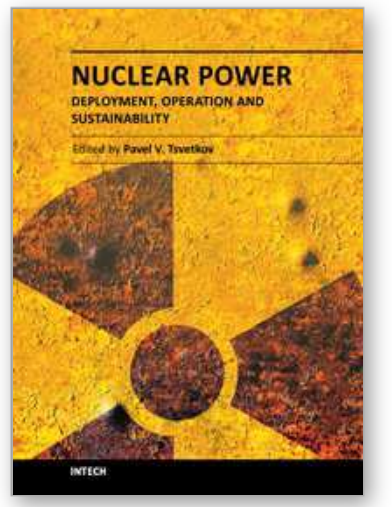

\author{
Nuclear Power - Deployment, Operation and Sustainability \\ Edited by Dr. Pavel Tsvetkov
}

ISBN 978-953-307-474-0

Hard cover, 510 pages

Publisher InTech

Published online 09, September, 2011

Published in print edition September, 2011

We are fortunate to live in incredibly exciting and incredibly challenging time. Energy demands due to economic growth and increasing population must be satisfied in a sustainable manner assuring inherent safety, efficiency and no or minimized environmental impact. These considerations are among the reasons that lead to serious interest in deploying nuclear power as a sustainable energy source. At the same time, catastrophic earthquake and tsunami events in Japan resulted in the nuclear accident that forced us to rethink our approach to nuclear safety, design requirements and facilitated growing interests in advanced nuclear energy systems. This book is one in a series of books on nuclear power published by InTech. It consists of six major sections housing twenty chapters on topics from the key subject areas pertinent to successful development, deployment and operation of nuclear power systems worldwide. The book targets everyone as its potential readership groups - students, researchers and practitioners - who are interested to learn about nuclear power.

\title{
How to reference
}

In order to correctly reference this scholarly work, feel free to copy and paste the following:

M. De Falco, A. Salladini, E. Palo and G. Iaquaniello (2011). Reformer and Membrane Modules (RMM) for Methane Conversion Powered by a Nuclear Reactor, Nuclear Power - Deployment, Operation and Sustainability, Dr. Pavel Tsvetkov (Ed.), ISBN: 978-953-307-474-0, InTech, Available from: http://www.intechopen.com/books/nuclear-power-deployment-operation-and-sustainability/reformer-andmembrane-modules-rmm-for-methane-conversion-powered-by-a-nuclear-reactor

\section{INTECH}

open science | open minds

\section{InTech Europe}

University Campus STeP Ri

Slavka Krautzeka 83/A

51000 Rijeka, Croatia

Phone: +385 (51) 770447

Fax: +385 (51) 686166

www.intechopen.com

\section{InTech China}

Unit 405, Office Block, Hotel Equatorial Shanghai

No.65, Yan An Road (West), Shanghai, 200040, China 中国上海市延安西路65号上海国际贵都大饭店办公楼405单元

Phone: +86-21-62489820

Fax: +86-21-62489821 
(C) 2011 The Author(s). Licensee IntechOpen. This chapter is distributed under the terms of the Creative Commons Attribution-NonCommercialShareAlike-3.0 License, which permits use, distribution and reproduction for non-commercial purposes, provided the original is properly cited and derivative works building on this content are distributed under the same license. 